\title{
Chemotherapy use and survival in stage II nasopharyngeal carcinoma
}

\author{
Xin-Bin Pan ${ }^{1}$, Shi-Ting Huang ${ }^{1}$, Kai-Hua Chen ${ }^{1}$ and Xiao-Dong Zhu ${ }^{1}$ \\ ${ }^{1}$ Department of Radiation Oncology, Cancer Hospital of Guangxi Medical University, Nanning, Guangxi 530021, P.R. China \\ Correspondence to: Xiao-Dong Zhu, email: zhuxiaodonggx@163.com
}

Keywords: nasopharyngeal carcinoma, chemotherapy, survival, stage II

Received: August 07, $2017 \quad$ Accepted: September 21, 2017

Published: October 11, 2017

Copyright: Pan et al. This is an open-access article distributed under the terms of the Creative Commons Attribution License 3.0 (CC BY 3.0), which permits unrestricted use, distribution, and reproduction in any medium, provided the original author and source are credited.

\section{ABSTRACT}

\begin{abstract}
Although common, the use of chemotherapy for stage II nasopharyngeal carcinoma (NPC) is controversial due to its undefined clinical benefits. We therefore conducted a retrospective cohort study to investigate whether chemotherapy confers survival gains to stage II NPC patients. A total of 251 stage II (2010 UICC/AJCC staging system) NPC patients treated between January 2007 and December 2014 were retrospectively analyzed. Patients were matched using the propensity-score matching method. The primary endpoint was overall survival (OS). Secondary endpoints were locoregional-free survival (LRFS) and distant metastasis-free survival (DMFS). Our analyses revealed no significant differences in OS, LRFS, or DMFS for stage II NPC patients treated with radiotherapy (RT) alone, concurrent chemoradiotherapy (CCRT), or CCRT + adjuvant chemotherapy (AC). T2N1 (OR = 6.690; 95\% CI, 3.091-14.481) and T1N1 (OR $=5.857 ; 95 \% \mathrm{CI}, 2.278-15.061)$ patients were more likely to receive CCRT than T2NO patients. Similarly, both T2N1 (OR = 10.513; 95\% CI, 3.439-32.137) and T1N1 (OR = 7.321; 95\% CI, 1.978-27.098) patients were more likely to receive CCRT + AC than T2NO patients. The present matched survival analysis suggests potential overuse of chemotherapy in stage II NPC, as the addition of chemotherapy did not provide a survival benefit in this group of patients.
\end{abstract}

\section{INTRODUCTION}

Nasopharyngeal carcinoma (NPC) is highly endemic in southern China $[1,2]$. Concurrent chemoradiotherapy (CCRT) with or without adjuvant chemotherapy (AC) is superior to radiotherapy (RT) alone in the treatment of locoregionally advanced NPC [3-8]. Although CCRT with or without AC is recommended for stage II NPC by the National Comprehensive Cancer Network [9], several studies suggested that chemotherapy use does not improve survival compared with RT alone [10-17]. The Chinese Anti-Cancer Association recommends RT alone for the T2N0 subgroup. For the T1N1 and T2N1 subgroups, RT with or without chemotherapy is reasonable $[11-14,18,19]$.

The incidence of stage II NPC has greatly increased with improvements in diagnosis. Although chemotherapy is not the standard treatment for stage II NPC, and its use remains controversial, a majority of stage II NPC patients are still receiving chemotherapy. Thus, it is possible that chemotherapy is overused in clinical practice without substantial survival gain. The objective of this retrospective cohort study was to assess whether chemotherapy use is associated with better survival in stage II NPC.

\section{RESULTS}

A total of 251 stage II NPC patients were included in this study. Among them, 94 received RT alone, 103 received CCRT, and 54 received $\mathrm{CCRT}+\mathrm{AC}$. The last follow-up was in October 2016. Median follow-up time was 64 months (12-116 months). The follow-up rate was $96.81 \%$ with 8 patients lost.

Chemotherapy and survival in stage II NPC

The 5-year OS, LRFS, and DMFS of stage II NPC patients treated with RT alone, CCRT, and CCRT $+\mathrm{AC}$ are shown in Table 1. Survival curves are shown in Figure 1. Pairwise comparisons revealed no significant differences 
in treatment outcomes for patients receiving RT alone, CCRT, or CCRT+AC, in both the unmatched and the propensity-matched cohorts.

The 5-year OS, LRFS, and DMFS of T1N1, T2N0, and T2N1 patients treated with RT alone, CCRT, and CCRT $+\mathrm{AC}$ are shown in Table 2. Here again, CCRT and CCRT + AC did not improve survival compared to RT alone. The propensity score-matching method was not performed because of the limited sampling size of the three subgroups.

\section{Survival among T1N1, T2N0, and T2N1 patients}

The 5-year OS, LRFS, and DMFS for the T1N1, T2N0, and T2N1 subgroups are shown in Table 3. No significant differences were found after pairwise comparisons among the three subgroups within both the unmatched and the propensity-matched cohorts.

\section{Chemotherapy use in stage II NPC}

For stage II NPC, $41.0 \%$ of the patients received CCRT, $21.5 \%$ received $\mathrm{CCRT}+\mathrm{AC}$, and $37.5 \%$ received RT alone. The percentage of patients receiving RT alone, CCRT, and CCRT $+\mathrm{AC}$ were, respectively, 30.43\%, $47.83 \%$, and $21.74 \%$ for $\mathrm{T} 1 \mathrm{~N} 1 ; 73.22 \%, 19.64 \%$, and $7.14 \%$ for T2N0; and $26.17 \%, 46.98 \%$, and $26.85 \%$ for T2N1 (Table 3).

With the T2N0 subgroup as reference, T1N1 patients were more likely to receive CCRT $(\mathrm{OR}=5.857 ; 95 \%$ $\mathrm{CI}, 2.278-15.061)$ and CCRT $+\mathrm{AC}(\mathrm{OR}=7.321 ; 95 \% \mathrm{CI}$, 1.978-27.098). Similarly, for T2N1 patients, the likelihood of receiving CCRT $(\mathrm{OR}=6.690 ; 95 \% \mathrm{CI}, 3.091-14.481)$ and $\mathrm{CCRT}+\mathrm{AC}(\mathrm{OR}=10.513 ; 95 \% \mathrm{CI}, 3.439-32.137)$ was higher than for T2N0 patients (Table 4).

\section{DISCUSSION}

Our study indicated no significant differences in OS, LRFS, and DMFS between stage II NPC patients treated with RT alone, CCRT, and CCRT + AC. Accordingly, our results suggest overuse of CCRT and AC for stage II NPC treatment.

Chemotherapy is not a standard treatment option for stage II NPC, and its use in these patients remains controversial. It was reported that survival of stage II NPC patients treated with 2D-CRT alone was not satisfactory [20-22]. In contrast, others suggested that chemotherapy addition translates into substantial improvements in DMFS and long-term OS [9, 23, 24]. However, these investigations used various TNM staging systems (Chinese 1992 or AJCC 2002) and T3 or N2 (AJCC 2010) patients might have been included. Thus, the referred results should be treated with caution. IMRT was expected to improve survival, but superiority of IMRT over 2D-CRT was not conclusively proved [25-29]. In fact, compared to 2D-CRT, IMRT only improved the quality of life in stage II NPC patients [30]. Luo et al. reported that CCRT had higher 3-year OS than IMRT alone $(100.0 \%$ vs $81.4 \%$, $P=0.04$ ) [31]. Moreover, a multi-center study suggested that CCRT improved 5-year LRFS and progression-free survival [32]. However, several retrospective cohort studies showed that IMRT alone was a reasonable option for stage II NPC whereas, in line with the present results, chemotherapy use failed to improve survival [10-12, 15-17].

Stage II NPC is divided into three subgroups (T1N1, T2N0, and T2N1). Our subgroup analysis results showed that compared to RT alone, CCRT and CCRT + AC did not improve survival in T1N1, T2N0, or T2N1. However, Guo et al. reported that chemotherapy
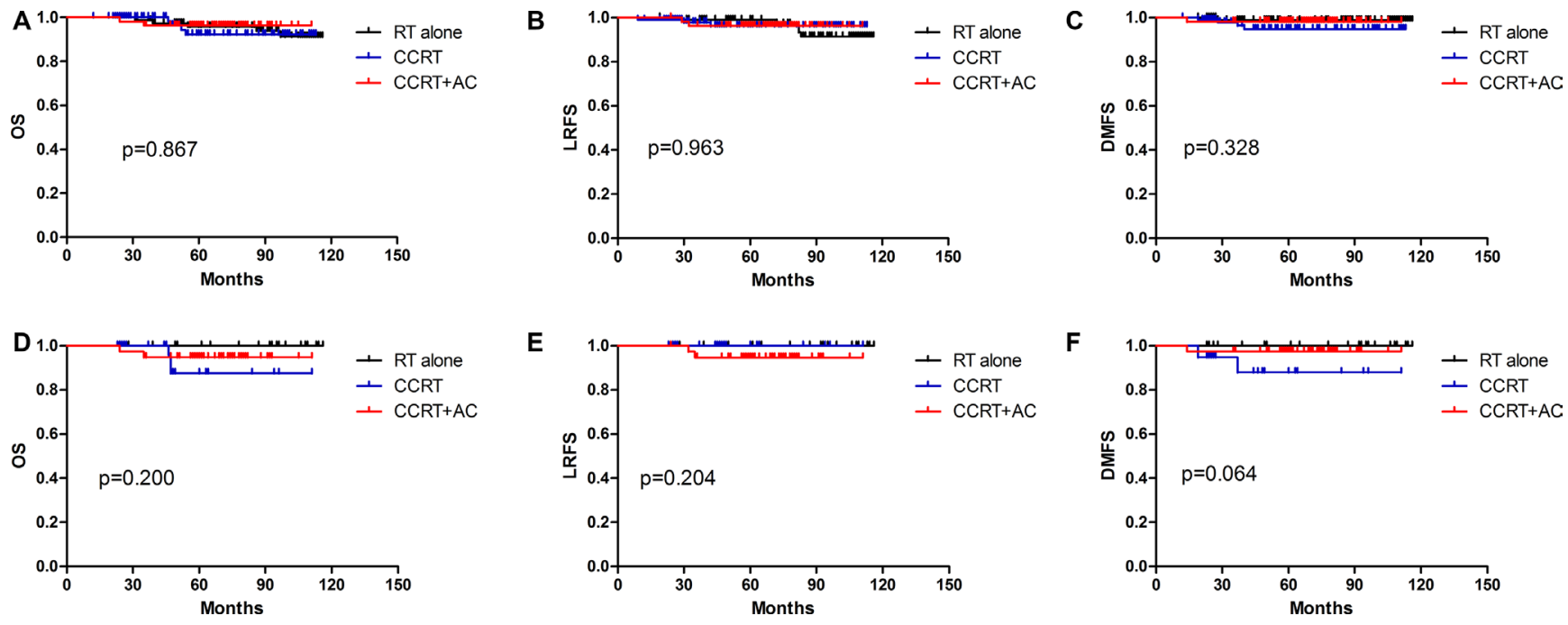

Figure 1: Kaplan-Meier survival curves of stage II nasopharyngeal carcinoma patients treated with radiotherapy (RT) alone, concurrent chemoradiotherapy (CCRT), and CCRT + adjuvant chemotherapy (CCRT+AC) in the unmatched cohort (A, B, C) and the propensitymatched cohort (D, E, F). Overall survival: OS; Locoregional-free survival: LRFS; Distant metastasis-free survival: DMFS. 
Table 1: Survival of stage II NPC patients treated with RT, CCRT, and CCRT+AC

\begin{tabular}{|c|c|c|c|c|c|c|c|c|}
\hline & \multicolumn{4}{|c|}{ Unmatched cohort } & \multicolumn{4}{|c|}{ Propensity-matched cohort } \\
\hline & RT $(n=94)$ & $\operatorname{CCRT}(n=103)$ & $\mathrm{CCRT}+\mathrm{AC}(n=54)$ & $P$ & RT $(n=38)$ & $\operatorname{CCRT}(n=38)$ & CCRT+AC $(n=38)$ & $P$ \\
\hline Age & $44(37.25,55.75)$ & $43(38.00,50.00)$ & $43.5(39.25,48.00)$ & 0.424 & $41(36.25,46.25)$ & $41(35.50,50.50)$ & $41.5(36.75,50.25)$ & 0.773 \\
\hline \multicolumn{9}{|l|}{ Sex } \\
\hline Female & 30 (31.91\%) & $32(31.07 \%)$ & $17(31.48 \%)$ & 1.000 & $10(26.32 \%)$ & $13(34.21 \%)$ & $13(34.21 \%)$ & 0.722 \\
\hline Male & $64(68.09 \%)$ & $71(68.93 \%)$ & $37(68.52 \%)$ & & $28(73.68 \%)$ & $25(65.79 \%)$ & $25(65.79 \%)$ & \\
\hline \multicolumn{9}{|l|}{ Pathology } \\
\hline WHO II & $8(8.51 \%)$ & $9(8.74 \%)$ & $9(16.67 \%)$ & 0.261 & $5(13.16 \%)$ & $5(13.16 \%)$ & $5(13.16 \%)$ & 1.000 \\
\hline WHO III & $86(91.49 \%)$ & $94(91.26 \%)$ & $45(83.33 \%)$ & & $33(86.84 \%)$ & $33(86.84 \%)$ & $33(86.84 \%)$ & \\
\hline \multicolumn{9}{|l|}{ Technique } \\
\hline IMRT & $51(54.26 \%)$ & $87(84.47 \%)$ & $40(74.07 \%)$ & 0.001 & $28(73.68 \%)$ & $28(73.68 \%)$ & $28(73.68 \%)$ & 1.000 \\
\hline 2D-CRT & $43(45.74 \%)$ & $16(15.53 \%)$ & $14(25.93 \%)$ & & $10(26.32 \%)$ & $10(26.32 \%)$ & $10(26.32 \%)$ & \\
\hline \multicolumn{9}{|l|}{ T stage } \\
\hline $\mathrm{T} 1$ & $14(14.89 \%)$ & $22(21.36 \%)$ & $10(18.52 \%)$ & 0.513 & $10(26.32 \%)$ & $4(10.53 \%)$ & $4(10.53 \%)$ & 0.131 \\
\hline $\mathrm{T} 2$ & $80(85.11 \%)$ & $81(78.64 \%)$ & $44(81.48 \%)$ & & $28(73.68 \%)$ & $34(89.47 \%)$ & $34(89.47 \%)$ & \\
\hline \multicolumn{9}{|l|}{$\mathrm{N}$ stage } \\
\hline No & $41(43.62 \%)$ & $11(10.68 \%)$ & $4(7.41 \%)$ & 0.001 & $4(10.53 \%)$ & $4(10.53 \%)$ & $4(10.53 \%)$ & 1.000 \\
\hline N1 & $53(56.38 \%)$ & $92(89.32 \%)$ & $50(92.59 \%)$ & & $34(89.47 \%)$ & $34(89.47 \%)$ & $34(89.47 \%)$ & \\
\hline \multicolumn{9}{|l|}{ AJCC stage } \\
\hline T1N1 & $14(14.89 \%)$ & $22(21.36 \%)$ & $10(18.52 \%)$ & 0.001 & $10(26.32 \%)$ & $4(10.53 \%)$ & $4(10.53 \%)$ & 0.342 \\
\hline T2N0 & $41(43.62 \%)$ & $11(10.68 \%)$ & $4(7.41 \%)$ & & $4(10.53 \%)$ & $4(10.53 \%)$ & $4(10.53 \%)$ & \\
\hline $\mathrm{T} 2 \mathrm{~N} 1$ & $39(41.49 \%)$ & $70(67.96 \%)$ & $40(74.07 \%)$ & & $24(63.15 \%)$ & $30(78.94 \%)$ & $30(78.94 \%)$ & \\
\hline \multicolumn{9}{|l|}{ Survival } \\
\hline OS & $95.9 \%$ & $92.2 \%$ & $96.3 \%$ & 0.867 & $100.0 \%$ & $87.5 \%$ & $94.7 \%$ & 0.200 \\
\hline LRFS & $98.9 \%$ & $96.1 \%$ & $96.2 \%$ & 0.963 & $100.0 \%$ & $100.0 \%$ & $94.6 \%$ & 0.204 \\
\hline DMFS & $98.7 \%$ & $94.8 \%$ & $98.1 \%$ & 0.328 & $100.0 \%$ & $88.0 \%$ & $97.4 \%$ & 0.064 \\
\hline
\end{tabular}

Abbreviations - NPC: nasopharyngeal carcinoma, RT: radiotherapy, CCRT: concurrent chemoradiotherapy, AC: adjuvant chemotherapy, IMRT: intensity-modulated radiotherapy, 2D-CRT: two-dimensional conventional radiotherapy, OS: overall survival, LRFS: locoregional-free survival, DMFS: distant metastasis-free survival.

improved LRFS in T1N1 [11]. In that report, the LRFS of T1N1 patients receiving chemotherapy or RT alone was $97.0 \%$ and $91.3 \%(p=0.017)$, respectively, although the improvement in LRFS did not translate into better DMFS or OS. Considering that no DMFS and OS benefits were achieved by chemotherapy, it may be appropriate to remove chemotherapy from T1N1 cases. In case of locoregional recurrence after RT alone, salvage treatments were still effective to control disease [33, 34].

The prognosis of $\mathrm{T} 1 \mathrm{~N} 1, \mathrm{~T} 2 \mathrm{~N} 0$, and $\mathrm{T} 2 \mathrm{~N} 1$ cases remains controversial. Xiao et al. reported that the 5-year OS for T1N1, T2N0, and T2N1 patients was $91.3 \%$, $85.8 \%$, and $73.1 \%(p<0.05)$ respectively [21]. Luo et al. also indicated that 3 -year OS was significantly poorer in $\mathrm{T} 2 \mathrm{~N} 1$ than in $\mathrm{T} 1 \mathrm{~N} 1$ and $\mathrm{T} 2 \mathrm{~N} 0$ patients $(74.5 \mathrm{vs} 100.0 \%$; $P=0.01$ ) [31]. Based on these data, T2N1 patients appear to constitute a unique subgroup characterized by worse survival. Potential interpretations of this phenomenon include: (1) Parapharyngeal extension increases the risk of distant metastasis [35-37], as 5-year DMFS of stage II NPC patients with parapharyngeal extension was reported to be $12.6 \%$ lower than in patients without this complication (73.6\% vs. $86.2 \%$ ) [37]. (2) N1 tumors carry a high risk of distant metastasis. Tang et al. reported that DMFS would decrease further when parapharyngeal extension occurred concurrently with positive lymph node metastasis (T2N1) [38]. According to these interpretations, clinicians might administrate more chemotherapy to T2N1 patients.

However, our study showed that 5-year DMFS for T1N1, T2N0, and T2N1 patients was $100.0 \%, 95.9 \%$, and $96.9 \%(p=0.500)$. Moreover, no differences were found between subgroups in 5-year LRFS and OS. Of note, several studies showed similar results $[10,11,14,15]$. Yet, despite much evidence that chemotherapy did not improve survival of stage II NPC, it was still widely used in clinical practices. Indeed, our data showed that the likelihood of receiving chemotherapy was higher for both $\mathrm{T} 2 \mathrm{~N} 1$ and T1N1 than for T2N0.

Our findings have significant clinical and economic implications. First, patients who received CCRT or CCRT + AC showed more acute and late toxicity reactions without a substantial survival benefit [8-10]. Second, compared to RT alone, CCRT impaired the quality of life of stage II NPC patients [39]. Third, because the cost of chemotherapy for NPC is high, overuse of chemotherapy imposes a considerable 
Table 2: Chemotherapy use and survival in T1N1, T2N0, and T2N1 subgroups

\begin{tabular}{llllll}
\hline & RT & CCRT & CCRT+AC & $p$ \\
\hline T1N1 & Total $(n=46)$ & $14(30.43 \%)$ & $22(47.83 \%)$ & $10(21.74 \%)$ & \\
& OS & $100.0 \%$ & $100.0 \%$ & $100.0 \%$ & 1.000 \\
& LRFS & $100.0 \%$ & $95.5 \%$ & $100.0 \%$ & 0.580 \\
T2N0 & DMFS & $100.0 \%$ & $100.0 \%$ & $100.0 \%$ & 1.000 \\
& Total $(n=56)$ & $41(73.22 \%)$ & $11(19.64 \%)$ & $4(7.14 \%)$ & 0.654 \\
& OS & $93.8 \%$ & $100.0 \%$ & $100.0 \%$ & 0.755 \\
& LRFS & $97.5 \%$ & $100.0 \%$ & $100.0 \%$ & 0.556 \\
& DMFS & $97.1 \%$ & $90.0 \%$ & $100.0 \%$ & 0.873 \\
& Total $(n=149)$ & $39(26.17 \%)$ & $70(46.98 \%)$ & $40(26.85 \%)$ & 0.858 \\
& OS & $96.6 \%$ & $88.4 \%$ & $95.0 \%$ & 0.383 \\
\hline
\end{tabular}

Abbreviations - RT: radiotherapy, CCRT: concurrent chemoradiotherapy, AC: adjuvant chemotherapy, OS: overall survival, LRFS: locoregional-free survival, DMFS: distant metastasis-free survival.

Table 3: Survival among T1N1, T2N0, and T2N1 subgroups

\begin{tabular}{|c|c|c|c|c|c|c|c|c|}
\hline & \multicolumn{4}{|c|}{ Unmatched cohort } & \multicolumn{4}{|c|}{ Propensity-matched cohort } \\
\hline & T1N1 $(n=46)$ & T2NO $(n=56)$ & T2N1 $(n=149)$ & $P$ & T1N1 $(n=21)$ & T2NO $(n=21)$ & T2N1 $(n=21)$ & $P$ \\
\hline Age & $42(38.00,47.00)$ & $45(36.50,54.25)$ & $44(39.00,52.00)$ & 0.516 & $42(39.00,47.00)$ & $40(35.00,47.00)$ & $41(38.00,47.00)$ & 0.905 \\
\hline \multicolumn{9}{|l|}{ Sex } \\
\hline female & $12(26.09 \%)$ & $20(35.71 \%)$ & $47(31.54 \%)$ & 0.591 & $6(28.57 \%)$ & $6(28.57 \%)$ & $7(33.33 \%)$ & 1.000 \\
\hline male & $34(73.91 \%)$ & $36(64.29 \%)$ & $102(68.46 \%)$ & & $15(71.43 \%)$ & $15(71.43 \%)$ & $14(66.67 \%)$ & \\
\hline \multicolumn{9}{|l|}{ Pathology } \\
\hline WHO II & $4(8.70 \%)$ & $4(7.14 \%)$ & $18(12.08 \%)$ & 0.598 & $1(4.76 \%)$ & $0(0.00 \%)$ & $1(4.76 \%)$ & 1.000 \\
\hline WHO III & $42(91.30 \%)$ & $52(92.86 \%)$ & $131(87.92 \%)$ & & $20(95.24 \%)$ & $21(100.00 \%)$ & $20(95.24 \%)$ & \\
\hline \multicolumn{9}{|l|}{ Technique } \\
\hline IMRT & $30(65.22 \%)$ & $30(53.57 \%)$ & $118(79.19 \%)$ & 0.001 & $12(57.14 \%)$ & $11(52.38 \%)$ & $12(57.14 \%)$ & 1.000 \\
\hline 2D-CRT & $16(34.78 \%)$ & $26(46.43 \%)$ & $31(20.81 \%)$ & & $9(42.86 \%)$ & $10(47.62 \%)$ & $9(42.86 \%)$ & \\
\hline \multicolumn{9}{|l|}{ Treatment } \\
\hline RT & $14(30.43 \%)$ & $41(73.22 \%)$ & $39(26.17 \%)$ & 0.000 & $9(42.86 \%)$ & $9(42.86)$ & $9(42.86 \%)$ & 0.966 \\
\hline CCRT & $22(47.83 \%)$ & $11(19.64 \%)$ & $70(46.98 \%)$ & & $9(42.86 \%)$ & $8(38.09 \%)$ & $10(47.62 \%)$ & \\
\hline $\mathrm{CCRT}+\mathrm{AC}$ & $10(21.74 \%)$ & $4(7.14 \%)$ & $40(26.85 \%)$ & & $3(14.28 \%)$ & $4(19.05 \%)$ & $2(9.52 \%)$ & \\
\hline \multicolumn{9}{|l|}{ Survival } \\
\hline OS & $100.0 \%$ & $95.6 \%$ & $93.5 \%$ & 0.165 & $100.0 \%$ & $94.4 \%$ & $100.0 \%$ & 0.509 \\
\hline LRFS & $97.8 \%$ & $98.2 \%$ & $96.6 \%$ & 0.588 & $95.2 \%$ & $95.2 \%$ & $100.0 \%$ & 0.999 \\
\hline DMFS & $100.0 \%$ & $95.9 \%$ & $96.9 \%$ & 0.500 & $100.0 \%$ & $94.7 \%$ & $100.0 \%$ & 0.378 \\
\hline
\end{tabular}

Abbreviations - RT: radiotherapy, CCRT: concurrent chemoradiotherapy, AC: adjuvant chemotherapy, IMRT: intensity-modulated radiotherapy, 2D-CRT: two-dimensional conventional radiotherapy, OS: overall survival, LRFS: locoregional-free survival, DMFS: distant metastasis-free survival

economic burden on society, especially in developing countries such as China [39].

Our study has some limitations that are worth considering: (1) Although we used the propensity scorematching method to reduce biases caused by confounding variables, confounding factors may still have influenced this retrospective cohort study. (2) The risk of treatment failure was very low in stage II NPC in the first five years. Thus, the follow-up time of this study might be insufficient for properly assessing survival. We are going to conduct a prospective, randomized control clinical trial (NCT02116231) to compare IMRT alone with IMRT and concurrent chemotherapy for the treatment of stage II NPC. The results of this trial should clarify whether addition of chemotherapy provides further survival benefits in this subset of patients. 
Table 4: Likelihood of receiving chemotherapy in the T1N1, T2N0, and T2N1 subgroups

\begin{tabular}{|c|c|c|c|c|c|c|c|c|}
\hline & \multicolumn{2}{|c|}{ CCRT } & \multirow{2}{*}{ ) } & \multirow{2}{*}{ OR (95\% CI) } & \multicolumn{2}{|c|}{$\mathrm{CCRT}+\mathrm{AC}$} & \multirow{2}{*}{$P$} & \multirow{2}{*}{ OR (95\% CI) } \\
\hline & yes & No & & & yes & no & & \\
\hline T2N0 & 11 & 41 & & 1 [Reference] & 4 & 41 & & 1 [Reference] \\
\hline T1N1 & 22 & 14 & 0.000 & $5.857(2.278-15.061)$ & 10 & 14 & 0.003 & $7.321(1.978-27.098)$ \\
\hline $\mathrm{T} 2 \mathrm{~N} 1$ & 70 & 39 & 0.000 & $6.690(3.091-14.481)$ & 40 & 39 & 0.000 & $10.513(3.439-32.137)$ \\
\hline
\end{tabular}

Abbreviations - CCRT: concurrent chemoradiotherapy, AC: adjuvant chemotherapy, OR: odds ratio, CI: confidence interval.

In conclusion, our study highlights a potential overuse of chemotherapy in the treatment of stage II NPC, as its addition to radiotherapeutic regimes did not result in survival improvement.

\section{MATERIALS AND METHODS}

\section{Study population}

A retrospective analysis was conducted in untreated NPC patients examined at the Cancer Hospital of Guangxi Medical University from January 2007 to December 2014. Patients without complete pretreatment evaluations, including pathology, nasopharyngoscopy, magnetic resonance imaging (MRI) or computed tomography (CT) scan of the nasopharynx and neck, chest radiography or CT scan, abdominal sonography or CT scan, and wholebody bone scan were excluded. Patients were restaged according to the 2010 International Union Against Cancer/ American Joint Committee on Cancer (UICC/AJCC) staging system [40].

\section{Radiotherapy and chemotherapy}

A detailed description of the radiotherapy modalities was published recently [29]. Total doses for gross tumor volumes were $66 \mathrm{~Gy}$ to $70 \mathrm{~Gy}$ for two-dimensional conventional radiotherapy (2D-CRT). The prescribed radiation doses of intensity-modulated radiotherapy (IMRT) were 66 Gy to 70.06 Gy for gross tumor volumes, and $54 \mathrm{~Gy}$ to $60 \mathrm{~Gy}$ for clinical tumor volumes.

Concurrent chemotherapy was scheduled on days 1 , 22 , and 43 with 80 to $100 \mathrm{mg} / \mathrm{m}^{2}$ of cisplatin for 1 or 3 days per cycle during radiotherapy. AC was 80 to $100 \mathrm{mg} /$ $\mathrm{m}^{2}$ of cisplatin for 1 or 3 days, and $600-750 \mathrm{mg} / \mathrm{m}^{2} / \mathrm{d}$ of 5 -fluorouracil in continuous intravenous infusion for 96 hours or 120 hours in a cycle of 28 days for 2 to 3 cycles. Chemotherapy was postponed or discontinued in patients who experienced serious toxicity and could not recover before the next scheduled cycle.

\section{Endpoints and follow-up}

The primary endpoint was overall survival (OS). Secondary endpoints were locoregional-free survival (LRFS) and distant metastasis-free survival (DMFS). OS, LRFS, and
DMFS were defined as the time interval from the first day of treatment until, respectively, the time of death, nasopharyngeal or regional lymph node relapse, or distant metastasis.

Patients were followed up every 3 months through the first 2 years, every 6 months for the next 3 years, and then annually. Physical examination, nasopharyngoscopy with/without biopsy, MRI or CT scan of the nasopharynx and neck, chest radiography or CT scan, and abdominal sonography or CT were performed. Bone scan was conducted if clinically indicated.

\section{Statistical analysis}

Continuous data were analyzed by student's $t$-test. Categorical variables were analyzed by chi-squared or Fisher's exact test. Survival was assessed using KaplanMeier plots with log-rank test statistics.

Based on the propensity score matching method, one-to-one nearest-neighbor matching was adopted to overcome selection bias among groups by use of a 0.1 caliper. The propensity score calculated by a logistic regression model represents the probability of each patient being assigned to each treatment group. Variables likely influencing survival, including age, sex, pathology, RT technique, T-stage, $\mathrm{N}$-stage, clinical stage, and treatment modality, were used in the score-matching method.

Statistical analyses were performed by IBM SPSS Statistics Version 23.0 (IBM Co., Armonk, NY, USA). Two-tailed $P<0.05$ were considered statistically significant.

\section{Ethical statement}

This study was approved by the Ethics Committee of the Cancer Hospital of Guangxi Medical University. Informed consent was obtained from the patients and/or guardians.

\section{Abbreviations}

NPC: nasopharyngeal carcinoma; RT: radiotherapy; CCRT: concurrent chemoradiotherapy; AC: adjuvant chemotherapy; IMRT: intensity-modulated radiotherapy; 2D-CRT: two-dimensional conventional radiotherapy; OS: overall survival; LRFS: locoregional-free survival; DMFS: distant metastasis-free survival. 


\section{Author contributions}

PXB and ZXD contributed to the conception of the study; HST contributed to manuscript preparation; $\mathrm{CKH}$ performed the data analyses; PXB, HST and CKH helped perform the analysis with constructive discussions.

\section{CONFLICTS OF INTEREST}

The authors declare no conflicts of interest.

\section{FUNDING}

This study was supported by the Basic Ability Improvement Project for Young and Middle-aged Teachers of Guangxi Zhuang Autonomous Region 2016 (No. KY2016LX029) and the Research and Development Project of Guangxi Medical and Health Appropriate Technology (No. S201514).

\section{REFERENCES}

1. Chen W, Zheng R, Baade PD, Zhang S, Zeng H, Bray F, Jemal A, Yu XQ, He J. Cancer statistics in China, 2015. CA Cancer J Clin. 2016; 66:115-32. https://doi.org/10.3322/ caac. 21338 .

2. Cao SM, Simons MJ, Qian CN. The prevalence and prevention of nasopharyngeal carcinoma in China. Chin J Cancer. 2011; 30:114-9.

3. Al-Sarraf M, LeBlanc M, Giri PG, Fu KK, Cooper J, Vuong T, Forastiere AA, Adams G, Sakr WA, Schuller DE, Ensley JF. Chemoradiotherapy versus radiotherapy in patients with advanced nasopharyngeal cancer: phase III randomized Intergroup study 0099. J Clin Oncol. 1998; 16:1310-7. https://doi.org/10.1200/JCO.1998.16.4.1310.

4. Chan AT, Teo PM, Ngan RK, Leung TW, Lau WH, Zee B, Leung SF, Cheung FY, Yeo W, Yiu HH, Yu KH, Chiu KW, Chan DT, et al. Concurrent chemotherapy-radiotherapy compared with radiotherapy alone in locoregionally advanced nasopharyngeal carcinoma: progressionfree survival analysis of a phase III randomized trial. J Clin Oncol. 2002; 20:2038-44. https://doi.org/10.1200/ JCO.2002.08.149.

5. Kwong DL, Sham JS, Au GK, Chua DT, Kwong PW, Cheng AC, Wu PM, Law MW, Kwok CC, Yau CC, Wan KY, Chan RT, Choy DD. Concurrent and adjuvant chemotherapy for nasopharyngeal carcinoma: a factorial study. J Clin Oncol. 2004; 22:2643-53. https://doi.org/10.1200/ JCO.2004.05.173.

6. Lin JC, Jan JS, Hsu CY, Liang WM, Jiang RS, Wang WY. Phase III study of concurrent chemoradiotherapy versus radiotherapy alone for advanced nasopharyngeal carcinoma: positive effect on overall and progression-free survival. J Clin Oncol. 2003; 21:631-7. https://doi.org/10.1200/ JCO.2003.06.158.
7. Wee J, Tan EH, Tai BC, Wong HB, Leong SS, Tan T, Chua ET, Yang E, Lee KM, Fong KW, Tan HS, Lee KS, Loong $\mathrm{S}$, et al. Randomized trial of radiotherapy versus concurrent chemoradiotherapy followed by adjuvant chemotherapy in patients with American Joint Committee on Cancer/ International Union against cancer stage III and IV nasopharyngeal cancer of the endemic variety. J Clin Oncol. 2005; 23:6730-8. https://doi.org/10.1200/JCO.2005.16.790.

8. Lee AW, Lau WH, Tung SY, Chua DT, Chappell R, Xu L, Siu L, Sze WM, Leung TW, Sham JS, Ngan RK, Law SC, Yau TK, et al, and Hong Kong Nasopharyngeal Cancer Study Group. Preliminary results of a randomized study on therapeutic gain by concurrent chemotherapy for regionallyadvanced nasopharyngeal carcinoma: NPC-9901 Trial by the Hong Kong Nasopharyngeal Cancer Study Group. J Clin Oncol. 2005; 23:6966-75. https://doi.org/10.1200/ JCO.2004.00.7542.

9. Chen QY, Wen YF, Guo L, Liu H, Huang PY, Mo HY, Li NW, Xiang YQ, Luo DH, Qiu F, Sun R, Deng MQ, Chen $\mathrm{MY}$, et al. Concurrent chemoradiotherapy vs radiotherapy alone in stage II nasopharyngeal carcinoma: phase III randomized trial. J Natl Cancer Inst. 2011; 103:1761-70. https://doi.org/10.1093/jnci/djr432.

10. Chen KH, Zhu XD, Li L, Qu S, Liang ZQ, Liang X, Pan XB, Liang ZG, Jiang YM. Comparison of the efficacy between concurrent chemoradiotherapy with or without adjuvant chemotherapy and intensity-modulated radiotherapy alone for stage II nasopharyngeal carcinoma. Oncotarget. 2016; 7:69041-50. https://doi.org/10.18632/oncotarget.11978.

11. Guo Q, Lu T, Lin S, Zong J, Chen Z, Cui X, Zhang Y, Pan J. Long-term survival of nasopharyngeal carcinoma patients with Stage II in intensity-modulated radiation therapy era. Jpn J Clin Oncol. 2016; 46:241-7. https://doi.org/10.1093/ jjco/hyv192.

12. $\mathrm{Xu} \mathrm{T}$, Shen $\mathrm{C}, \mathrm{Zhu} \mathrm{G}, \mathrm{Hu}$ C. Omission of Chemotherapy in Early Stage Nasopharyngeal Carcinoma Treated with IMRT: A Paired Cohort Study. Medicine (Baltimore). 2015; 94:e1457. https://doi.org/10.1097/MD.0000000000001457.

13. Tham IW, Lin S, Pan J, Han L, Lu JJ, Wee J. Intensitymodulated radiation therapy without concurrent chemotherapy for stage IIb nasopharyngeal cancer. Am J Clin Oncol. 2010; 33:294-9. https://doi.org/10.1097/ COC.0b013e3181d2edab.

14. Su SF, Han F, Zhao C, Chen CY, Xiao WW, Li JX, Lu TX. Long-term outcomes of early-stage nasopharyngeal carcinoma patients treated with intensity-modulated radiotherapy alone. Int J Radiat Oncol Biol Phys. 2012; 82:327-33. https://doi.org/10.1016/j.ijrobp.2010.09.011.

15. Su Z, Mao YP, Tang J, Lan XW, OuYang PY, Xie FY. Longterm outcomes of concurrent chemoradiotherapy versus radiotherapy alone in stage II nasopharyngeal carcinoma treated with IMRT: a retrospective study. Tumour Biol. 2016; 37:4429-38. https://doi.org/10.1007/s13277-015-4266-5.

16. Chua DT, Ma J, Sham JS, Mai HQ, Choy DT, Hong MH, Lu TX, Au GK, Min HQ. Improvement of survival after 
addition of induction chemotherapy to radiotherapy in patients with early-stage nasopharyngeal carcinoma: Subgroup analysis of two Phase III trials. Int J Radiat Oncol Biol Phys. 2006; 65:1300-6. https://doi.org/10.1016/j. ijrobp.2006.02.016.

17. Song $\mathrm{CH}$, Wu HG, Heo DS, Kim KH, Sung MW, Park CI. Treatment outcomes for radiotherapy alone are comparable with neoadjuvant chemotherapy followed by radiotherapy in early-stage nasopharyngeal carcinoma. Laryngoscope. 2008; 118:663-70. https://doi.org/10.1097/ MLG.0b013e3181626cfe.

18. Lang J, Gao L, Guo Y, Zhao C, Zhang C, and Society of Head \& Neck Tumor Surgery, and Society of Radiation Therapy, and Chinese Anti-Cancer Association. Comprehensive treatment of squamous cell cancer of head and neck: Chinese expert consensus 2013. Future Oncol. 2014; 10:1635-48. https://doi.org/10.2217/fon.14.44.

19. Pan XB, Zhu XD. Role of chemotherapy in stage IIb nasopharyngeal carcinoma. Chin J Cancer. 2012; 31:573-8. https://doi.org/10.5732/cjc.011.10433.

20. Chua DT, Sham JS, Kwong DL, Au GK. Treatment outcome after radiotherapy alone for patients with Stage I-II nasopharyngeal carcinoma. Cancer. 2003; 98:74-80. https:// doi.org/10.1002/cncr.11485.

21. Xiao WW, Han F, Lu TX, Chen CY, Huang Y, Zhao C. Treatment outcomes after radiotherapy alone for patients with early-stage nasopharyngeal carcinoma. Int J Radiat Oncol Biol Phys. 2009; 74:1070-6. https://doi. org/10.1016/j.ijrobp.2008.09.008.

22. He X, Ye M, Guo X, Pan Z, Zhang Z, He S, Liu T. Treatment outcome of patients with stages I-II nasopharyngeal carcinoma after late course accelerated hyperfractionation radiotherapy alone. Oral Oncol. 2012; 48:1058-63. https:// doi.org/10.1016/j.oraloncology.2012.05.008.

23. Cheng SH, Tsai SY, Yen KL, Jian JJ, Chu NM, Chan KY, Tan TD, Cheng JC, Hsieh CY, Huang AT. Concomitant radiotherapy and chemotherapy for early-stage nasopharyngeal carcinoma. J Clin Oncol. 2000; 18:2040-5. https://doi.org/10.1200/JCO.2000.18.10.2040.

24. Xu T, Hu C, Wang X, Shen C. Role of chemoradiotherapy in intermediate prognosis nasopharyngeal carcinoma. Oral Oncol. 2011; 47:408-13. https://doi.org/10.1016/j. oraloncology.2011.03.008.

25. Marta GN, Silva V, de Andrade Carvalho H, de Arruda FF, Hanna SA, Gadia R, da Silva JL, Correa SF, Vita Abreu $\mathrm{CE}$, Riera R. Intensity-modulated radiation therapy for head and neck cancer: systematic review and meta-analysis. Radiother Oncol. 2014; 110:9-15. https://doi.org/10.1016/j. radonc.2013.11.010.

26. Co J, Mejia MB, Dizon JM. Evidence on effectiveness of intensity-modulated radiotherapy versus 2-dimensional radiotherapy in the treatment of nasopharyngeal carcinoma: Meta-analysis and a systematic review of the literature. Head Neck. 2016 (Suppl 1); 38:E2130-42. https://doi. org/10.1002/hed.23977.
27. Peng G, Wang T, Yang KY, Zhang S, Zhang T, Li Q, Han J, $\mathrm{Wu} \mathrm{G}$. A prospective, randomized study comparing outcomes and toxicities of intensity-modulated radiotherapy vs. conventional two-dimensional radiotherapy for the treatment of nasopharyngeal carcinoma. Radiother Oncol. 2012; 104:286-93. https://doi.org/10.1016/j.radonc.2012.08.013.

28. OuYang PY, Shi D, Sun R, Zhu YJ, Xiao Y, Zhang LN, Zhang XH, Chen ZY, Lan XW, Tang J, Gao YH, Ma J, Deng W, et al. Effect of intensity-modulated radiotherapy versus two-dimensional conventional radiotherapy alone in nasopharyngeal carcinoma. Oncotarget. 2016; 7:33408-17. https://doi.org/10.18632/oncotarget.8573.

29. Pan XB, Chen KH, Huang ST, Jiang YM, Ma JL, Liang ZG, Qu S, Li L, Chen L, Zhu XD. Comparison of the efficacy between intensity-modulated radiotherapy and two-dimensional conventional radiotherapy in stage II nasopharyngeal carcinoma. Oncotarget. 2017; 8:7809678104. https://doi.org/10.18632/oncotarget.17481.

30. Pan XB, Huang ST, Chen KH, Jiang YM, Ma JL, Qu S, Li L, Chen L, Zhu XD. Intensity-modulated radiotherapy provides better quality of life than two-dimensional conventional radiotherapy for patients with stage II nasopharyngeal carcinoma. Oncotarget. 2017; 8:4621146218. https://doi.org/10.18632/oncotarget.17582.

31. Luo S, Zhao L, Wang J, Xu M, Li J, Zhou B, Xiao F, Long $\mathrm{X}$, Shi M. Clinical outcomes for early-stage nasopharyngeal carcinoma with predominantly WHO II histology treated by intensity-modulated radiation therapy with or without chemotherapy in nonendemic region of China. Head Neck. 2014; 36:841-7. https://doi.org/10.1002/hed.23386.

32. Kang MK, Oh D, Cho KH, Moon SH, Wu HG, Heo DS, Ahn YC, Park K, Park HJ, Park JS, Keum KC, Cha J, Kim JW, et al. Role of Chemotherapy in Stage II Nasopharyngeal Carcinoma Treated with Curative Radiotherapy. Cancer Res Treat. 2015; 47:871-8. https://doi.org/10.4143/crt.2014.141.

33. Hua YJ, Han F, Lu LX, Mai HQ, Guo X, Hong MH, Lu TX, Zhao C. Long-term treatment outcome of recurrent nasopharyngeal carcinoma treated with salvage intensity modulated radiotherapy. Eur J Cancer. 2012; 48:3422-8. https://doi.org/10.1016/j.ejca.2012.06.016.

34. Cheah SK, Lau FN, Yusof MM, Phua VC. Treatment outcome with brachytherapy for recurrent nasopharyngeal carcinoma. Asian Pac J Cancer Prev. 2014; 14:6513-8.

35. Teo P, Lee WY, Yu P. The prognostic significance of parapharyngeal tumour involvement in nasopharyngeal carcinoma. Radiother Oncol. 1996; 39:209-21.

36. Xiao GL, Gao L, Xu GZ. Prognostic influence of parapharyngeal space involvement in nasopharyngeal carcinoma. Int J Radiat Oncol Biol Phys. 2002; 52:957-63.

37. Chua DT, Sham JS, Kwong DL, Choy DT, Au GK, Wu PM. Prognostic value of paranasopharyngeal extension of nasopharyngeal carcinoma. A significant factor in local control and distant metastasis. Cancer. 1996; 78:202-10. https://doi.org/10.1002/(SICI)10970142(19960715)78:2<202::AID-CNCR3>3.0.CO;2-N. 
38. Tang LL, Sun Y, Mao YP, Chen Y, Li WF, Chen L, Liu LZ, Lin AH, Li L, Ma J. Prognostic value of parapharyngeal extension in nasopharyngeal carcinoma treated with intensity modulated radiotherapy. Radiother Oncol. 2014; 110:404-8. https://doi.org/10.1016/j.radonc.2013.10.007.

39. Pan XB, Huang ST, Chen KH, Jiang YM, Ma JL, Qu S, Li L, Chen L, Zhu XD. Concurrent chemoradiotherapy degrades the quality of life of patients with stage II nasopharyngeal carcinoma as compared to radiotherapy. Oncotarget. 2017; 8:14029-38. https://doi.org/10.18632/ oncotarget.14932.

40. Edge SB, Compton CC. The American Joint Committee on Cancer: the 7th edition of the AJCC cancer staging manual and the future of TNM. Ann Surg Oncol. 2010; 17:1471-4. https://doi.org/10.1245/s10434-010-0985-4. 